\title{
ESTIMATING PM2.5 IN XI'AN, CHINA USING AEROSOL OPTICAL DEPTH OF NPP VIIRS DATA AND METEOROLOGICAL MEASUREMENTS
}

\author{
Kainan Zhang ${ }^{\mathrm{a}}$, Zhiqiang Yang, ${ }^{\mathrm{a},}$, Jun Zheng, ${ }^{\mathrm{a}}$ Jiao Jiashuanga, Gao Wangwang ${ }^{\mathrm{a}}$ \\ ${ }^{a}$ College of Geological Engineering and Surveying, Chang'an University, 710054 Xi'an, China - \\ zkn0312@foxmail.com, yang_gps@chd edu.cn, 2568791196@qq.com,jjshuang@chd.edu.cn,631695269@qq.com
}

Commission III, WG III/8

KEY WORDS: Aerosol optical depth, PM2.5, VIIRS, Remote sensing inversion, Nonlinear model

\begin{abstract}
:
In recent years, the air pollution is becoming more and more serious, which not only causes the decrease of the visibility, but also affects the human health. As the most important pollutant particulate matter, remote sensing satellite measurements have been widely used to estimate PM2.5 concentration on the ground. Visible Infrared Imaging Radiometer Suite (VIIRS) is one of the instruments which is taken in the National Polar-orbiting Partnership (NPP) satellite. In this study, VIIRS was used to retrieve aerosol optical depth (AOD) with the way of dark pixels, and several other major meteorological variables (wind speed, relative humidity, $\mathrm{NO}_{2}$ concentration, ground surface relative humidity and planetary boundary layer height) were combined with AOD to construct a nonlinear multiple regression mode for establishing the relationship between AOD and PM2.5 concentration. The North Basin of Shaanxi province of China, which includes Xi'an, is located in the north of Qinling Mountains, south of the Loess Plateau, and in the central of Weihe basin, with special structure and other adverse weather conditions (static wind, less rain ) to cause the frequent haze weather in Xi'an. Xi'an city was selected as the area of the experiment due to its particularity. This research obtained the AOD results from August 1, 2013 to October 30, 2013. The inversion results were compared with ground-based PM2.5 concentration date from air quality monitoring station of $\mathrm{Xi}$ 'an. The result showed that there is a significant correlation between the two, and the correlation coefficient is 0.783 . The inversion result verified that the model of VIIRS data agreed well AOD, which could be used to estimate the surface PM2.5 concentration and monitor the regional air quality.
\end{abstract}

\section{INTRODUCTION}

Atmospheric aerosol as a multiphase system is composed of solid, liquid particles and gas, which affect the climate and ecosystem of the earth. Aerosol is an important component of the terrestrial atmosphere ocean system, it determines the microphysical properties of clouds, and it could change the radiation process of gas system. Aerosol can change the atmospheric chemical processes, and affect the concentration and distribution of greenhouse gases (Kaufman, 2001). Atmospheric aerosol also has an important impact on human health, aerosol particles could enter the respiratory tract with human respiratory activity, and partly of them are deposited in the lung to cause lesions. Among them, Particulate Matter 2.5 (PM2.5) refers to aerodynamic equivalent diameter of particles less than $2.5 \mu \mathrm{m}$. It can be transmitted over a long distance and stay in the air for a long time, it will reduce visibility, affect traffic safety, pollute the environment, and damage people's respiratory system, and the health effects of these aerosols have attracted widespread attention in the medical community.

Satellite remote sensing is one of the main ways of atmospheric aerosol monitoring, it has advantages of stereo observation system, wide coverage and real-time acquisition. MISR aerosol optical depth (AOD) in the visible light and near infrared band inversion is very close to the particle size of PM2.5, which provided a theoretical foundation for establishing relationship of AOD-PM2.5 (Kahn, 1998). The vertical profile of AOD is an important factor influencing the AOD-PM2.5 relationship after studies using MODIS and MISR AOD data to estimate the global PM2.5 concentration distribution in 2001 (Van Donkelaar,2006, 2010). The geographically weighted regression model (GWR) was built to estimate the concentration of PM2.5 in the southeastern United States, and the results showed that the GWR model had higher prediction accuracy (Hu, 2013). However, the MODIS has exceeded its service time, NASA has launched a new type of sensor for earth observation.

National Polar-orbiting Operational Environmental Satellite System (NPOESS) Preparatory Project (NPP) was launched in October 28, 2011, affiliation to The Joint Polar Satellite System (JPSS), it was developed by the NASA, the NOAA and the United States Air force. Visible and Infrared Imager Radiometer Suite (VIIRS) is a sensor equipped on the NPP satellite, it could collect radiation images of land, atmosphere, ice and ocean in the visible and infrared band. VIIRS satellite reference to the advantages of MODIS and SeaWiFS satellites, providing 22 visible and infrared channel to observe the marine ecosystem evolution, marine climate and ecological change. Like the MODIS satellite, it is the polar orbiting satellite that transits the equator at about 13:30 local time, while the VIIRS satellite has the higher resolution. In China, the researches about VIIRS sensor data are relatively small. Xi'an is located in the Shaanxi Province of China, the south of Qinling Mountains and the north of the Loess Plateau, it is located in the Guanzhong Basin in the middle of Weihe River Basin, with special structure and other adverse weather conditions (static wind, less rain ) to cause the frequent haze weather in Xi'an. The winds of the suburbs are blown into the city, these winds have transported to urban air pollution and suburban transported back to the city, making the pollutions of surrounding urban and more remote place into the city, it plays a catalytic role in the formation of haze phenomenon. Based on this, this study focus on Xi'an, uses VIIRS to derive AOD, 
combining the meteorological factors to build a nonlinear model for estimating PM2.5 concentration.

\section{DATE AND METHODS}

\subsection{DATA}

2.1.1 Ground PM2.5 measurements: Ground PM2.5 measurements in Xi'an from August 1, 2013 to October 31, 2013 were collected from the official web site of the China Environmental Monitoring Center system (CEMC) (http://113.108.142.147:20035/emcpublish/) and the Green Breathing website(http://www.pm25.com/xian.html). According to the environmental protection standard of China, the ground PM2.5 data for China's mainland were measured by the tapered element oscillating microbalance (TEOM) method. More than 13 ambient air quality monitoring stations were set up in Xi'an by the Ministry of Environmental Protection (MEP) MEP. This study uses daily-mean PM2.5 mass concentrations $\left(\mu \mathrm{g} / \mathrm{m}^{3}\right)$. The PM2.5 mass concentrations with an accuracy of $\pm 1.5 \mu \mathrm{g} / \mathrm{m}^{3}$ for the hourly average and of $\pm 0.5 \mu \mathrm{g} / \mathrm{m}^{3}$ for the daily average.

2.1.2 NPP VIIRS satellite data: VIIRS is mainly used for global observations of land, sea, and atmospheric parameters. VIIRS is an optical system consisting of the SeaWiFS front optical instrument and the MODIS /THEMIS of post optical instrument. VIIRS has 22 channels (Schueler, 2013), 9 channels of them are in the visible near infrared $(0.4-0.9 \mu \mathrm{m}), 8$ channels are in the short / medium wave infrared $(1-4 \mu \mathrm{m}), 4$ channels are in thermal infrared $(8-12 \mu \mathrm{m})$, one is in visible light channel under low illumination. The channels used for AOD inversion are 4 channels $(0.488 \mu \mathrm{m}), 11$ channels $(1.240 \mu \mathrm{m})$ and 15 channels $(2.250 \mu \mathrm{m})$, and they are inherited from the EOS /MODIS sensor. The spatial resolution of the VIIRS EDR data is $6 \mathrm{~km} \times 6 \mathrm{~km}$. We used the EDR to collect the AOD data from August 1, 2013 to October 30, 2013 in Xi' an; these data can be downloaded from the larger array-data stewardship system (http://www.class.ngdc.noaa.gov/saa/products/welcome). This paper retrieved aerosol optical depth of land based on dark pixel method. First of all, we identified the dark pixels according to the normalized difference vegetation index (NDVI) in the infrared spectrum; then we used 6S software to build lookup tables by radiative transfer calculation; finally, according to the VIIRS data and the look-up table, we interpolated the AOD and corrected the elevation.

2.1.3 Ground-based meteorogical measurementes and $\mathrm{NO}_{2}$ data: In order to match the observation time of NPP satellite, the PM2.5 data corresponding to VIIRS transit time (10:30) within half an hour (from 10:00 to 11:00) were studied in this paper. Ground-based meteorological parameters, including wind speed (WS), surface temperature (ST) and surface relative humidity $(\mathrm{RH})$, were obtained from two meteorological stations in Xi'an and Jinghe, we can download the data at the China Meteorological Administration Meteorological Observatory Network (http://data.cma.cn/). This article downloaded $\mathrm{NO}_{2}$ data in the Xi'an from August 1, 2013 to October 30, 2013 (http://www.temis.nl/airpollution/no2col/ no2regioomi_v2.php).

2.1.4 HPBL data: It's difficult to monitor HPBL, it is not a conventional surface meteorological variable. We use the HPBL from the NCEP reanalysis, which is from the Climate Forecast System (CFS) model. CFS model can be found at its website (http://cfs.ncep.noaa.gov/).

\subsection{Inversion model}

At present, the researches mainly focuses on the definition and observation of haze and climate characteristics in China, and the studies of particles mainly focuses on particle size distribution, pollution level, temporal and spatial distribution, chemical composition and source apportionment. However, there is not much research on the invention of PM2.5 based on NPP satellite remote sensing AOD. The current researches are based on AOD to establish polynomial linear regression or nonlinear statistical model. Previous studies have shown that the meteorological conditions can strongly impact regression models for the AOD - PM2.5 relationship. Thus, a number of methods were proposed to use meteorological factors to improve the relationship between AOD and ground-level PM2.5 (Koelemeijer et al., 2006; Liu et al., 2007a, 2007b; Tian and Chen, 2010; Wang et al., 2010). In addition, $\mathrm{NO}_{2}$ also has an impact on PM2.5. Therefore, based on the influence of meteorological factors and aerosol on PM2.5, a nonlinear regression logarithm is established in this paper:

$$
\begin{array}{r}
\begin{array}{r}
\ln (P M 2.5)=\beta_{0}+\beta_{1} \ln (A O D)+\beta_{2} \ln (f(R H))+\beta_{3} \ln (S T) \\
+\beta_{4} \ln (W S)+\beta_{5} \ln (H P B L)+\beta_{6} N O_{2}
\end{array} \\
f(R H)=\frac{1}{1-R H / 100}
\end{array}
$$

Where PM2.5 represents PM2.5 mass concentration near the ground per day $\left(\mu \mathrm{g} / \mathrm{m}^{3}\right), \beta_{0}$ is the intercept, AOD are obtained by VIIRS inversion (unitless), $\beta_{1}-\beta_{6}$ are the regression coefficients about predictor variables, including $A O D$, relative humidity $(\%)$, surface temperature $\left({ }^{\circ} \mathrm{C}\right)$, wind seed $(\mathrm{m} / \mathrm{s})$, HPBL (m), $\mathrm{NO}_{2}\left(10^{15}\right.$ molec $\left./ \mathrm{cm}^{2}\right)$, respectively.

\section{RESULTS AND DISCUSSION}

\subsection{Direct correlation analysis between AOD and observed PM2.5}

Since the rainy weather, fog pollution and winter surface reflectance changes will lead to loss of $\mathrm{AOD}$, and reduce the valid days of AOD, we should exclude data of cloud pollution and select valid date of AOD and PM2.5 for a total of 73 from August 1, 2013 to October 30, 2013, e. g. Table 1.

\begin{tabular}{|c|c|c|c|}
\hline Month & August & September & October \\
\hline NO. & 24 & 23 & 26 \\
\hline
\end{tabular}

Table1. Valid data pairs for AOD and PM2.5

We can find out the relationship about VIIRS AOD and observed PM2.5 concentration, their direct linear correlation is lower, e. g. Figure 1 , the correlation coefficient $\mathrm{R}$ of three months were $0.42,0.47$ and $0.43\left(\mathrm{R}^{2}=0.17,0.24\right.$ and 0.18$), \quad \mathrm{R}$ for a total of 73 was $0.42\left(\mathrm{R}^{2}=0.17\right)$. In this paper, further research is needed under the meteorological factors. 


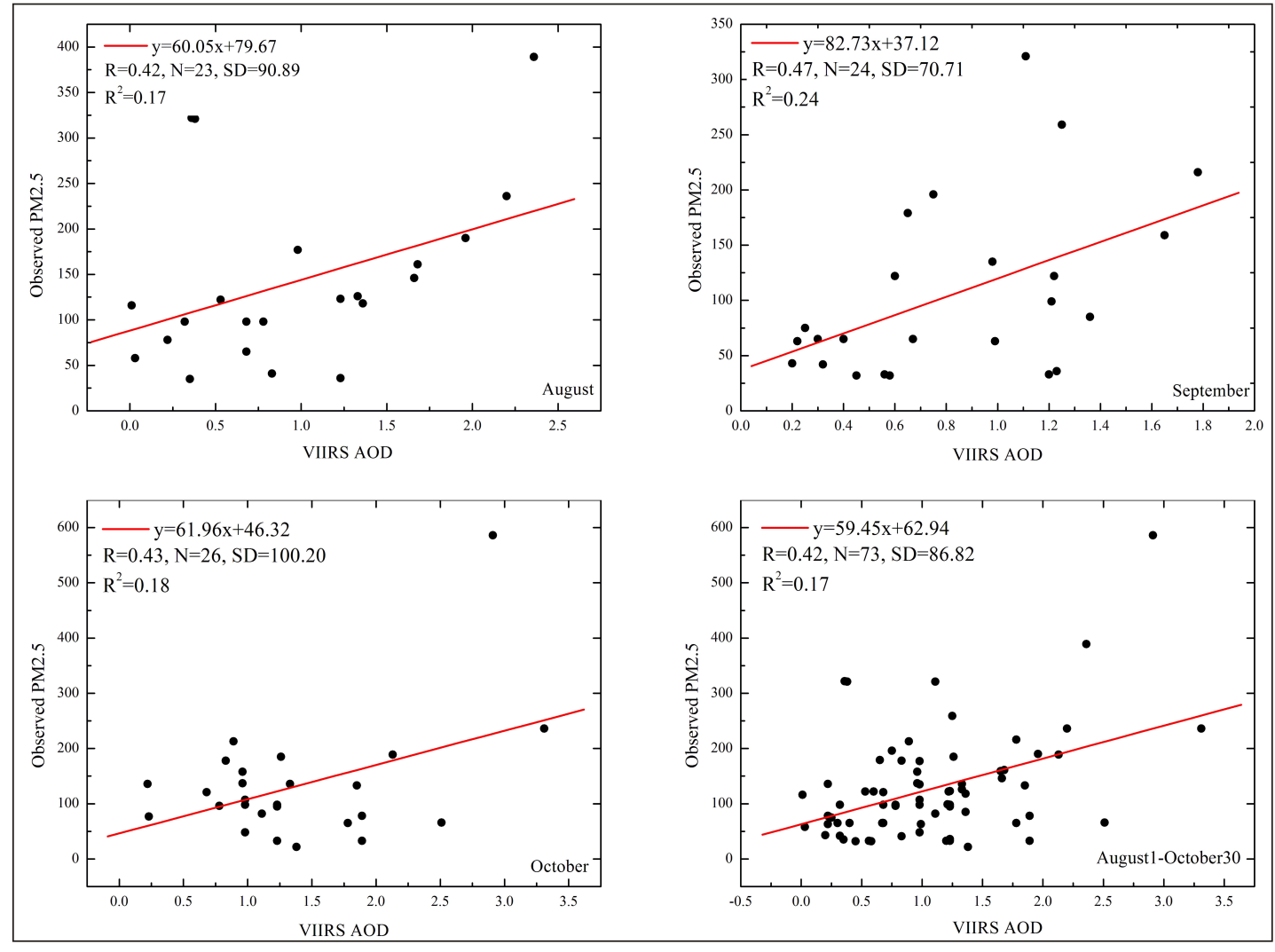

Figure 1. Scatter plots of VIIRS AOD vs. Observed PM2.5

\subsection{Correlation analysis between predicted PM2.5 and observed PM2.5}

The regression coefficients of the nonlinear model Eq. (1) are shown in Table 2, and the positive coefficients indicate that the predictors are positively correlated with PM2.5, and the negative coefficients indicate that they are negatively related to PM2.5, which can be explained as follows. First, AOD is related to particles' light extinction, so high RH can enhance the size and light extinction efficiency of hygroscopic particles, such as ammonium sulfates and ammonium nitrates. Therefore, under the same AOD value, the actual PM2.5 value in wet environment is lower than that in drying situation. Second, as the PM2.5 is vertically mixed, the higher the planetary boundary layer, the lower the PM2.5 concentration near the ground. Third, as the temperature increasing, atmospheric particulates may evaporate and PM2.5 concentrations will decrease. Similarly, high wind speed can contribute to the diffusion of pollutants. Finally, the release of $\mathrm{NO}_{2}$ is accompanied by automobile exhaust and fuel combustion. These human activities are also one of the major factors that increase PM2.5, so higher PM2.5 concentration is related to $\mathrm{NO}_{2}$ in some degree.

In this paper, data of meteorological and HPBL are taken into Eq. (1), and the scatter plots of predicted PM2.5 and observed PM2.5 correlation are obtained, e.g. Figure 2. We found that adding correction factors of meteorological factors, correlation coefficients of observation PM2.5 and prediction are improved, the three months of the $\mathrm{R}$ were $0.81,0.79$ and $0.74\left(\mathrm{R}^{2}=0.66,0.64\right.$ and 0.55$), \quad \mathrm{R}$ of the three months for a total of 73 was $0.78\left(R^{2}=0.61\right)$. The model estimates a monthly average PM2.5 concentration of $122.57 \mu \mathrm{g} / \mathrm{m}^{3}$, approximately $7 \%$ lower than the monthly mean of in situ measurements $\left(113.99 \mu \mathrm{g} / \mathrm{m}^{3}\right)$. Especially in October, monitoring the concentration of PM2.5 approximately $12 \%$ higher than the predicted PM2.5, this may be because the weather is cold in October of Xi'an, some areas begin burning coal for heating, and causing air pollution, and occasionally sudden sandstorms increase PM2.5 concentrations. The overall forecast concentration decline can be explained as follows. First, the poor representative of the HPBL in the model might cause some bias. The temporal and spatial resolutions of the HPBL data are relatively coarse, which might not capture the actual episodes in HPBL very well during VIIRS satellite overpass. Furthermore, it is possible that multiple layers of aerosols are present in the atmosphere; these aerosols contribute more toward the total AOD than the surface-layer aerosols, and AOD and PM2.5 might not be well correlated under multiple layers of aerosols (Gupta and Christopher, 2009).

\begin{tabular}{|c|c|c|}
\hline $\begin{array}{c}\text { Model } \\
\text { predictors }\end{array}$ & $\begin{array}{c}\text { Coefficient } \\
\left(\beta_{\mathrm{i}}\right)\end{array}$ & $\begin{array}{c}\mathrm{P} \\
\text { value }\end{array}$ \\
\hline intercept & 7.212 & $<0.0001$ \\
\hline $\mathrm{Ln}(\mathrm{AOD})$ & 0.421 & $<0.0005$ \\
\hline $\mathrm{Ln}(\mathrm{f}(\mathrm{RH}))$ & -0.017 & $<0.0001$ \\
\hline $\mathrm{Ln}(\mathrm{ST})$ & -0.053 & $<0.0001$ \\
\hline $\mathrm{Ln}(\mathrm{WS})$ & -0.125 & $<0.0001$ \\
\hline $\mathrm{Ln}(\mathrm{HPBL})$ & -0.315 & $<0.0001$ \\
\hline $\mathrm{NO}_{2}$ & 0.031 & $<0.0001$ \\
\hline
\end{tabular}

Table 2. Variable coefficients of nonlinear models 


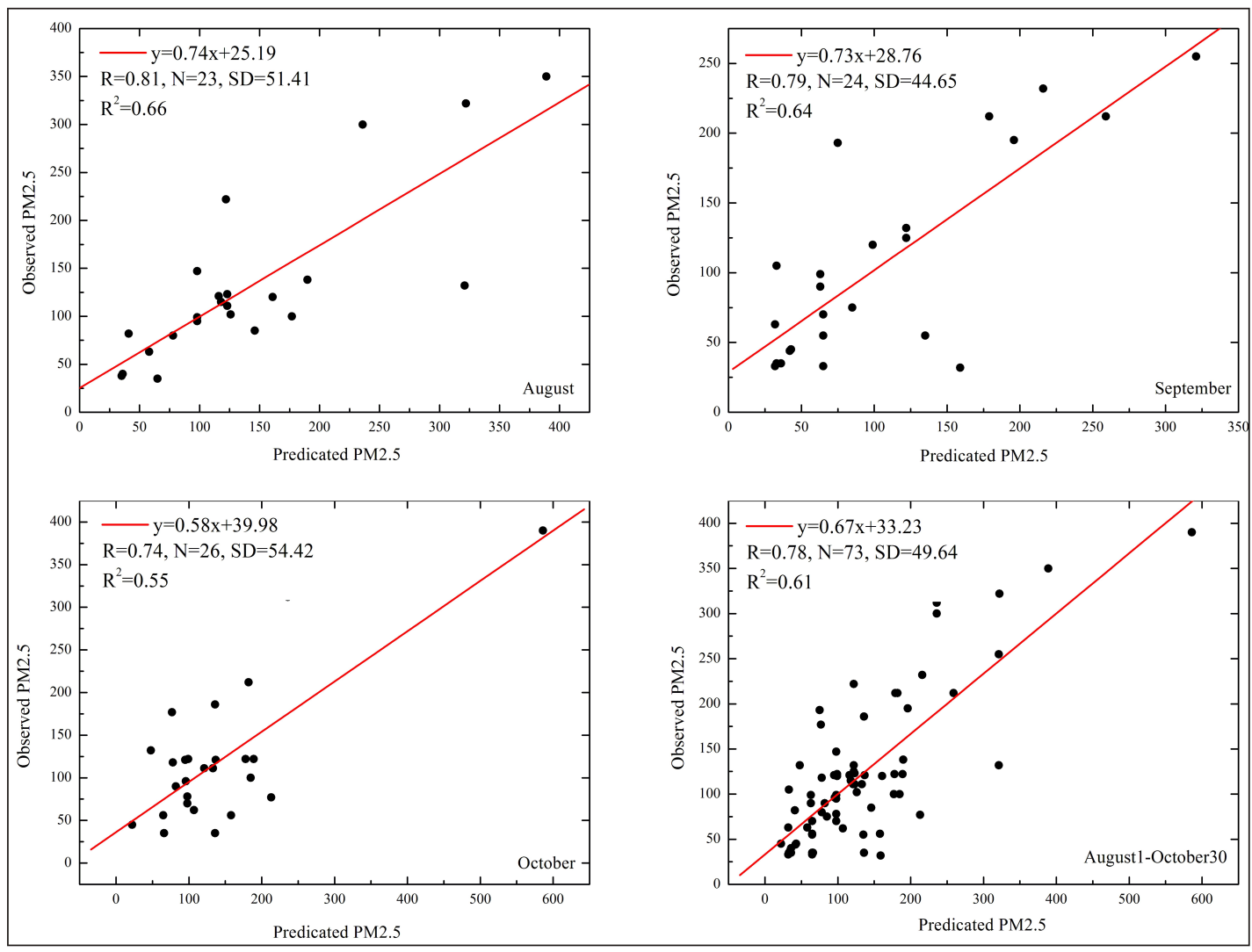

Figure 1. Scatter plots of Predicated PM2.5 vs. Observed PM2.5

\section{CONCLUSIONS}

The influence of meteorological factors such as HPBL, relative humidity plays an important role on the correlation between AOD and PM2.5, AOD-PM2.5 direct linear correlation was 0.42. After creating model prediction concentration model with meteorological factors and $\mathrm{NO}_{2}$ concentration, the correlation between observation and prediction of PM2.5 increased to 0.78 .

The seasonal variation characteristics of the correlation between PM2.5 observation and predicted are also obvious. The summer (August - September) has a higher correlation. In autumn (October) the correlation declines, which reveals the influence of meteorological factors on the relationship between AOD and PM2.5 both in different seasons and different mechanisms, also shows that the seasonal differences in physical and chemical properties of AOD and PM2.5 source.The logarithmic inversion model can accurately retrieve near ground PM2.5 mass concentration based on VIIRS AOD and meteorological factors in this paper, it provides the possibility for satellite remote sensing monitoring near ground PM2.5. At the same time, in this study, we only used three months of data, there was no consideration of seasonal and interannual variations, so the future study need longer time series inversion of PM2.5 concentration, we could correct factors and parameters of model, and improve the stability and precision of inversion model, which will be the next step in the research work.

\section{ACKNOWLEDGEMENTS}

This work was supported by Fundamental Research Funds for the Central Universities (310826175027, 310826175018). VIIRS data were obtained from the Atmosphere Archive and Distribution System at NASA/Goddard Space Flight Center.

\section{REFERENCES}

Gupta P, Christopher SA, 2009. Particulate matter air quality assessment using integrated surface, satellite, and meteorological products: Multiple regression approach. $J$ Geophys Res, 114:D14205.

Kahn R, Banerjee P, McDonald D, Diner DJ, 1998. Sensitivity ofmultiangle imaging to aerosol optical depth and to pureparticle size distribution and composition over ocean. $J$ Geophys Res, 103:32195 - 213.

Hu X, Waller LA, Al-Hamdan MZ, Crosson WL, Estes Jr MG, Estes SM, 2013. Estimating groundlevel PM2.5 concentrations in the southeastern U.S. using geographically weighted regression. Environ Res, 121:1 - 10.

Koelemeijer RBA, Homan CD, Matthijsen J., 2006. Comparison of spatial and temporal variations of aerosol optical thickness and particulate matter in Europe. Atmos Environ, $\quad 40: 5304-15$. 
Liu Y, Franklin M, Kahn R, Koutrakis P., 2007a. Using aerosol optical thickness to predict groundlevel PM2.5 concentrations in the St. Louis area: a comparison between MISR and MODIS Remote Sens Environ, 107:33 - 44.

Liu Y, Koutrakis P, Kahn R., 2007b. Estimating fine particulate matter component concentrations and size distributions using satellite-retrieved fractional aerosol optical depth: part1-method development. J Air Waste Manage Assoc, 57:1351 - 9.

Kaufman YJ, Tanré D, Boucher O., 2002. A satellite view of aerosols in the climate system. Nature, 419:215 - 23.

Schueler C F, Lee T F and Miller S D., 2013. VIIRS constant spatial-resolution advantages. International Journal of Remote Sensing, 34(16) : 5761-5777.
Tian J, Chen D., 2010. A semi-empiricalmodel for predicting hourly ground-level fine particulate matter (PM2.5) concentration in southern Ontario from satellite remote sensing and ground-based meteorological measurements. Remote Sens Environ, 114:221 - 9 .

Van Donkelaar A, Martin RV, Park RJ, 2006. Estimating ground level PM2.5 using aerosol optical depth determined from satellite remote sensing. J Geophys Res, 111:D21201.

Van Donkelaar A, Martin RV, BrauerM, Kahn R, Levy R, Verduzco C, et al., 2010. Global estimates of ambient fine particulate matter concentrations from satellite-based aerosol optical depth: development and application. Environ Health Perspect, 118:847 - 55. 